\title{
The impact of educational intervention on physical activity, nutrition and laboratory parameters in type II diabetic patients
}

\author{
Aghbabak Maheri ${ }^{1}$, Maryam Asnaashari ${ }^{2}$, Hamid Joveini $^{1}$, Azar Tol $^{3}$, Ali Asghar Firouzian ${ }^{4}$, Alireza Rohban $^{5}$
}

${ }^{1}$ Ph.D. Candidate in Health Education and Promotion, Faculty of Public Health, Tehran University of Medical Sciences, Tehran, Iran

${ }^{2}$ M.Sc. in Health Education Faculty of Public Health, Hamedan University of Medical Sciences, Hamedan, Iran

${ }^{3}$ Ph.D. in Health Education and Promotion, Faculty of Public Health, Tehran University of Medical Sciences, Tehran, Iran

${ }^{4}$ M.Sc. in Nursing, Educator, Esfarayan University of Medical Sciences, Esfarayen, Iran

${ }^{5}$ M.Sc. in Rehabilitation Management, School of Rehabilitation, Iran University of Medical Sciences, Tehran, Iran

\section{Type of article: Original}

\begin{abstract}
Background: Diabetes is one of the most common chronic diseases that is now widely spread around the world, and day by day the number of patients is increasing. The purpose of this study was to determine the impact of educational intervention on physical activity, nutrition and laboratory parameters in type 2 diabetic patients.

Methods: This semi-experimental study was performed from March to October 2015 on 100 patients with type 2 diabetes who referred to the Niknejad health center. The type of sampling was simple random. Data were collected using a questionnaire including demographic questions, assessment of nutritional status and physical activity, history of diabetes, physical measurements and laboratory parameters of patients. Data were analyzed using SPSS 16, and descriptive and analytical tests (paired-samples t-test) and the results were significant at the level of $(\mathrm{p}<0.05)$.

Results: In present study, body measurements, the mean number of units of fruit and vegetable intake per day, type of oil consumption, the mean number of days of fish intake per week or the mean number of days with intense physical activity per week, had no significant difference before and after the intervention, while the variables of FBS level $(p<0.003)$, rate of $\mathrm{HbA}_{1 \mathrm{c}}(\mathrm{p}<0.027)$, the mean number of days of fruit intake $(\mathrm{p}<0.001)$ and vegetable intake $(p<0.037)$ per week and the mean number of days with moderate physical activity $(p<0.03)$ of patients, had significant difference before and after the intervention.

Conclusion: According to the findings of this study, to improve BMI, fish intake, type of oil consumption and also increased daily fruit and vegetable intake in these patients, a variety of educational-supportive interventions are recommended.

Keywords: Educational Intervention, Diabetes, Physical Activity, Nutrition, Laboratory parameters
\end{abstract}

\section{Introduction}

In recent decades, the prevalence and incidence pattern of diseases has changed from infectious diseases to chronic diseases (1). Diabetes is one of the most common chronic diseases that is now widely spread around the world and day by day the number of patients is increasing (2). Diabetes is one of the most important non-infectious diseases around the world. Due to increased life expectancy, urbanization, an increase in the prevalence of obesity and overall changes in people's lifestyle, the prevalence of diabetes is increasing steadily (3). Genetic predisposition, family history of diabetes, environmental factors, physical inactivity, poor nutrition, and obesity are risk factors for diabetes (4). Different lifestyles such as physical activity rate and diet vary between the different regions and ethnic groups living in those regions, and exert an influence on the pattern of type 2 diabetes. It seems that environmental

\section{Corresponding author:}

Hamid Joveini, Faculty of Public Health, Tehran University of Medical Sciences, Tehran, Iran.

Tel: +98.9155853375, Email: hamidjoveyni124@gmail.com

Received: October 24, 2016, Accepted: November 28, 2016, Published: April 2017

iThenticate screening: November 23, 2016, English editing: January 06, 2017, Quality control: January 18, 2017

(C) 2017 The Authors. This is an open access article under the terms of the Creative Commons Attribution-NonCommercialNoDerivs License, which permits use and distribution in any medium, provided the original work is properly cited, the use is non-commercial and no modifications or adaptations are made. 
changes related to urbanization and lifestyle have played an important role in the epidemic of type 2 diabetes in the world (5). Several studies have been accomplished in Iran and the world about the prevalence and risk factors of type 2 diabetes that shows that researchers and officials need to have a clear image about the condition of type 2 diabetes in society (6). Estimates show that in 2000, 171 million people had diabetes worldwide and this number will reach 366 million by 2030 (6). According to the World Health Organization, the prevalence of diabetes in Iran in 1990, 1995 and 2015, were 5.5\%, 7.5\% and 8.6\% respectively and according to this estimation, the population of our country in the mentioned years will be 1,692,000, 1,977,000 and 5,125,000 (7). Today, diabetes not only in Iran but also throughout the world is increasing so that now there are 300 million people with diabetes worldwide (8). An important fact to remember is that non-pharmaceutical treatment strategies are as effective as pharmaceuticals in a diabetic patient's treatment and prevention of disease complications. Teaching proper nutrition intake and regular physical activity are the basis of non-pharmaceutical treatment (9). Following regimen and lifestyle changes are very important factors to control the disease in type 2 diabetic patients. But it should be noted that it is very difficult to meet this goal and it requires the use of multilateral interventions and partnership between various departments (1011). Due to the long-term and chronic nature of diabetes and limitations in healthcare systems, patients are responsible for a large part of the process of controlling the disease. Self-care has always been noteworthy throughout history in all societies and it is defined as provided care by the patient and his family. Regarding the limitations of the healthcare system, the history of self-care programs date back to 1960s and 70s (12). Diabetics are always advised to follow self-care programs to control blood sugar and ultimately to protect and promote their health. Self-care programs entail following a special regimen, including sports activities, and intermittent periodic checkups to diagnose diabetes complications early on, blood sugar monitoring, daily intake of prescribed medication as instructed and some other changes in lifestyle (13). One of the biggest challenges in healthcare systems is nonadherence of regimen and self-care behavior which imposes significant costs to the patient's care system. Age, sex, education, psychological characteristics, knowledge, attitude, skills, self-efficacy, and empowerment are individual factors which can impact on adherence to self-care programs in patients with type 2 diabetes (14). Therefore, health education and training programs play an important role to help diabetics follow self-care programs and a healthy lifestyle, because the purpose of health education and promotion is to create awareness and to promote attitudes, skills and self-efficacy of individuals in order to have a healthy lifestyle. Basically, without a plan, health education and promotion efforts will be ineffective (15-16). Education can help patients to control type 2 diabetes in a way that education has an influence on nutritional patterns and type of physical activity and their daily life, so undoubtedly training is a fundamental part in controlling the disease, but it should be an ongoing process throughout life (17). According to the above, this study aimed to determine the impact of educational intervention on physical activity, nutritional patterns and laboratory parameters in patients with type 2 diabetes who referred to Niknejad health center in Shahr-e-Rey in 2015 ( Niknejad health center was selected because of the high number of patients covered, and easier access to patients).

\section{Material and Methods}

This semi-experimental study was a before and after study to determine the impact of an educational intervention on physical activity, nutritional patterns and laboratory parameters in patients with type 2 diabetes, who referred to Niknejad health center in Shahr-e-Rey in 2015. The statistical population of this study was people (about 2000 patients) who had diabetes type 2, covered by Niknejad health center in 2015 . Inclusion criteria for the study consisted of informed consent for the study and lack of severe complications of diabetes. Exclusion criteria consisted of the occurrence of an adverse event or any of the complications of diabetes for one during the study which prevents the person from participating in the study and disinclination of one to continue participating in the study. According to the formula, the sample size with the power of $80 \%$ and confidence level of $95 \%$ was estimated to be 140. The samples were selected with a simple random group of patients who had their medical record in Niknejad health center. We called them and invited them to participate in the study. Among 140 patients, 100 patients volunteered to participate in the study. The data collection tool was a questionnaire including demographic questions (Age, sex, occupation, income), questions assessing a patient's nutritional status, physical activity, history of diabetes, physical measurements (height, weight, BMI, waist circumference) and laboratory parameters (fasting blood sugar and glycated hemoglobin level in the blood). To assess fruit and vegetable intake, first, we asked the number of days of fruit and vegetable intake in a typical week, and then the mean intake in one of the days of that week. In this study, the physical activity with moderate intensity is the kind of activity that is at least 10 minutes long, is continuous, and requires a slight increase in breathing and heart rate (18), such as fast walking, riding a bike (recreational and slow), swimming, badminton and recreational rowing. In this study, the physical activity with high intensity is the kind of activity that is at least 10 minutes long, is continuous and requires a severe increase in breathing and heart rate (18), such as running, weightlifting, martial arts, basketball, soccer, volleyball, rapid 
cycling, skiing, tennis and fast rowing. In order to assess laboratory parameters (fasting blood sugar and glycated hemoglobin), before and 3 months after the educational intervention, we invited a lab technician to bleed and analyze blood samples of patients. The questionnaire reliability was $81 \%$ and there was test-retest method on 20 patients within two weeks. The questionnaire validity was measured by using the content validity and reliable books and sources, and with the help of clear-sighted experts. Before the educational intervention, data were collected and then educational intervention was done in 4 groups of 25 members in Diabetes Education Classes over a four-week period )four educational sessions, 45-60 minutes for each session) in forms of lecture, Q\&A, group discussion, power point program, and posters and pamphlets in the health center. Educational content was prepared based on the book "Non-infectious Diseases; Care and country program for prevention and control of diabetes" which is available in all health centers and the country's health-networks. At the end of each session, educational content was also given to the patients in the form of pamphlets and posters. Three months after the educational intervention, patients were evaluated again and gathered data were compared for before and three months after the educational intervention. Data were analyzed using SPSS version 16 (SPSS Inc., Chicago, Illinois, USA) and descriptive and analytical tests (paired-samples t-test) and the results were significant at the level of $(p<0.05)$.

\section{Results}

In this study, 100 people were studied and the response was 100 percent. The mean age of participants was $56 \pm 9.8$ and the mean monthly income was $530 \pm 1.9$ thousand Tomans, $33 \%$ of patients were male. In this study, the occupation of most patients (64\%) had been reported as housekeeper (Table 1). In the present study, the mean weight of participants, before and after the educational intervention was $74 \pm 1.27 \mathrm{~kg}$ and $73.35 \pm 1.2 \mathrm{~kg}$ respectively. Based on the results of the paired-samples t-test, this difference was not statistically significant. The mean waist circumference of participants, before and after the educational intervention was $96.16 \pm 9.18 \mathrm{~cm}$ and $95.68 \pm 8.71 \mathrm{~cm}$ respectively and it was not statistically significant, based on the results of the paired-samples t-test. Also, the body mass index of participants, before and after the educational intervention was $28.82 \pm 4.43 \mathrm{~kg} . \mathrm{m}^{2}$ and $28.57 \pm 4.19$ $\mathrm{kg} . \mathrm{m}^{2}$ respectively and it was not statistically significant based on the results of the paired-samples t-test. In the present study, the mean benchmark of participants' fasting blood sugar before and after the educational intervention was $169.26 \pm 59.21 \mathrm{mg}$. $\mathrm{dl}$ and $146.96 \pm 46.02 \mathrm{mg}$. dl respectively, and it was statistically significant based on the results of the paired-samples t-test $(\mathrm{p}<0.003)$ and also the mean of glycated hemoglobin of participants before and after the educational intervention was statistically significant $(p<0.027)($ Table 2$)$. In the present study, the mean number of units of fruit intake per day, before and after the educational intervention was $1.37 \pm 0.05$ and $1.38 \pm 0.05$ respectively and it was not statistically significant, though the mean number of days of fruit intake per week, before and after the educational intervention among the participants was statistically significant $(\mathrm{p}<0.001)$. Also, the mean number of units of vegetable intake per day, before and after the educational intervention was $1.07 \pm 0.07$ and 1.06 \pm 0.25 respectively and it was not statistically significant based on the results of the paired-samples t-test though the mean number of units of vegetable intake per week, before and after educational intervention among the participants was statistically significant $(\mathrm{p}<0.037)$. In this study, before the educational intervention, most of the participants (79\%) reported that they consume liquid vegetable oil, and after the educational intervention most of the participants $(89 \%)$ reported that they consume vegetable oil likewise. Before the educational intervention, among all participants, only one patient (1\%) reported eating fish at least once a week, whereas after the educational intervention two patients $(2 \%)$ reported eating fish once a week (Table 3,4$)$. The mean number of days per week with intense physical activity in participants was 1 before the educational intervention and 1.5 after the educational intervention, and it was not significant based on the results of the paired-samples t-test. Moreover, the mean number of days per week with moderate physical activity in participants was 1.75 before the educational intervention and 2.73 after the educational intervention, and it was statistically significant $(\mathrm{p}<0.03)$ (Table 5).

Table 1. Absolute and relative frequency distribution of demographic characteristics of patients

\begin{tabular}{|l|l|l|l|}
\hline Demographic variable & $\mathrm{n}$ & $\%$ \\
\hline Sex & Male & 33 & 33 \\
\cline { 2 - 4 } & Female & 67 & 67 \\
\cline { 2 - 4 } & Total & 100 & 100 \\
\hline Occupations status & Self-employment & 7 & 7 \\
\cline { 2 - 4 } & Housekeeper & 64 & 64 \\
\cline { 2 - 4 } & Retired & 23 & 23 \\
\cline { 2 - 4 } & unemployed & 1 & 1 \\
\cline { 2 - 4 } & Other occupations & 4 & 4 \\
\hline
\end{tabular}


http://www.ephysician.ir

Table 2. The mean and standard deviation of physical measurements and laboratory parameters of participants (before and 3 months after the educational intervention)

\begin{tabular}{|l|l|l|l|l|l|}
\hline \multirow{2}{*}{ Variable } & \multicolumn{2}{|l|}{ Before intervention } & \multicolumn{2}{l|}{ 3 months after intervention } & \multirow{2}{*}{ p-value } \\
\cline { 2 - 5 } & Mean & SD & Mean & SD & \\
\hline Weight $(\mathrm{kg})$ & 74 & 1.27 & 73.35 & 1.20 & 0.95 \\
\hline Waist circumference $(\mathrm{cm})$ & 96.16 & 9.18 & 95.68 & 8.71 & 0.09 \\
\hline $\mathrm{BMI}^{1}(\mathrm{~kg} / \mathrm{m})$ & 28.82 & 4.43 & 28.57 & 4.19 & 0.68 \\
\hline $\mathrm{FBS}^{2}(\mathrm{mg} / \mathrm{dl})$ & 169.26 & 59.21 & 146.96 & 46.02 & 0.003 \\
\hline $\mathrm{HbA}_{1 \mathrm{c}}{ }^{3}(\%)$ & 8.34 & 1.70 & 7.33 & 1.45 & 0.027 \\
\hline
\end{tabular}

1: Body Mass Index; 2: Fasting Blood Sugar; 3: Glycated Hemoglobin

Table 3 Nutritional status of the participants (before and 3 months after the educational intervention)

\begin{tabular}{|l|l|l|l|l|l|}
\hline \multirow{2}{*}{ Variable } & \multicolumn{3}{|l|}{ Before intervention } & \multicolumn{3}{l|}{ 3 months after intervention } & \multirow{2}{*}{-value } \\
\cline { 2 - 5 } & Mean & SD & Mean & SD & \\
\hline Units of fruit intake per day (n) & 1.37 & 0.05 & 1.38 & 0.05 & 0.97 \\
\hline Units of fruit intake per week (n) & 2.9 & 1.12 & 3.95 & 1 & 0.001 \\
\hline Units of vegetable intake per day (n) & 1.07 & 0.07 & 1.06 & 0.25 & 0.28 \\
\hline Units of vegetable intake per week (n) & 1.91 & 1.08 & 2.22 & 0.92 & 0.037 \\
\hline
\end{tabular}

Table 4. Nutritional status of the participants (before and 3 months after the educational intervention)

\begin{tabular}{|c|c|c|c|c|c|c|}
\hline \multirow[t]{2}{*}{ Variable } & \multirow[t]{2}{*}{ 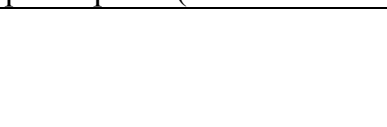 } & \multicolumn{2}{|c|}{ Before intervention } & \multicolumn{2}{|c|}{$\begin{array}{l}3 \text { months after } \\
\text { intervention }\end{array}$} & \multirow[t]{2}{*}{$\mathrm{p}$-value } \\
\hline & & Total & $\%$ & Total & $\%$ & \\
\hline \multirow[t]{3}{*}{ Type of oil consumption } & Solid vegetable oil & 11 & 11 & 6 & 6 & \multirow[t]{3}{*}{0.34} \\
\hline & Liquid vegetable oil & 79 & 79 & 89 & 89 & \\
\hline & Other & 10 & 10 & 55 & & \\
\hline \multirow{2}{*}{$\begin{array}{l}\text { The number of days of fish } \\
\text { intake per week }\end{array}$} & At least once & 1 & 1 & 2 & 2 & \multirow[t]{2}{*}{0.56} \\
\hline & Not knowing or not eating & 99 & 99 & 98 & 98 & \\
\hline
\end{tabular}

Table 5. Physical activity status of the participants (before and 3 months after the educational intervention)

\begin{tabular}{|l|l|l|l|l|l|l|}
\hline Variable & Before intervention & 3 month after intervention & p-value \\
\cline { 2 - 6 } & Mean & SD & Mean & SD & \\
\hline $\begin{array}{l}\text { The number of days of the week with intense } \\
\text { physical activity }\end{array}$ & 1 & 0 & 1.50 & 0.70 & 0.27 \\
\hline $\begin{array}{l}\text { The number of days of the week with } \\
\text { moderate physical activity }\end{array}$ & 1.75 & 0.75 & 2.73 & 0.76 & 0.03 \\
\hline
\end{tabular}

\section{Discussion}

With regard to the importance of diet and having appropriate physical activity to control blood sugar, in this study we checked the nutritional status and physical activity status of type 2 diabetic patients and its impact on physical measurements (weight, waist circumference and body mass index) and laboratory parameters (fasting blood sugar and glycated hemoglobin). Based on the findings of this study, the mean daily units of fruit and vegetable intake, before the educational intervention was 1.37 and 1.07 respectively which is lower than the recommended units based on the food pyramid of the United States Department of Agriculture (USDA) (19). In the study carried out by Farvid and his colleagues, the mean number of units of fruit and vegetable intake amongst type 2 diabetic patients was 3.01 and 2.95 respectively (20), which is more than the findings of our study. Due to the importance of fruit and vegetable intake among diabetics, to control blood sugar level (20), this amount of daily fruit and vegetable intake (1.37 and 1.07), among the participants is not acceptable. Nutritional therapy such as regular and standard intake of fruit and vegetables is a necessary and inseparable part of the therapeutic program in a way that, based on the results of various studies, there was a reverse effect between the amount of fruit and vegetable intake and fasting blood sugar and glycated hemoglobin level (21). Also, more than two units of fruit and vegetable intake per day can reduce diabetes complications (22). The importance of fruit and vegetable intake on blood sugar control and on preventing diabetes complications has been proven through many studies (21-24), so by identifying factors affecting fruit and vegetable intake among diabetics, it is recommended to do various types of educational-supportive interventions, in order to increase the number of units of fruit and vegetable intake among these patients. Based on the results of this 
study, the mean number of units of daily fruit and vegetable intake in participants, before and after the educational intervention, was not statistically significant, hence, it can be said that the applied educational intervention has not been effective in increasing the number of units of daily fruit and vegetable intake amongst type 2 diabetic patients. To increase fruit and vegetable intake, individualized educational interventions are not enough to enhance the awareness and to change the attitude, so the supportive interventions such as reduction in food and vegetable price, to increase access to fresh fruits and vegetables should be done to cut existing obstacles such as high price of food and vegetables, economic and social situation and lack of time for $f$ fruit and vegetable intake (25). Due to the importance of the daily intake of 2-4 units of fruit and 3-5 units of vegetable for type 2 diabetics (20) and with regard to the point that the effectiveness of educational interventions depends on the appropriate use of existing theories and patterns in health education and health promotion (26), it is recommended to design and apply varieties of theory-based educational-supportive interventions to enhance fruit and vegetable intake among these patients. According to the findings of the present study, the mean number of days of fruit intake per week, was 2.9 before the educational intervention and reached 3.95 after the educational intervention and it was statistically significant, and the mean number of days of vegetable intake was 1.91 and reached 2.22 after the educational intervention and it was statistically significant as well. These results reveal that the applied educational intervention has been effective to increase the number of days of food and vegetable intake per week among type 2 diabetic patients.

Many studies show the effectiveness of the educational interventions on improving the nutritional status of diabetic patients, such as the studies conducted by Kashfi and colleagues about the effect of educating about nutrition and jogging, on the blood sugar of type 2 diabetic patients of Nader Kazemi clinic in Shiraz (17), Heydari and colleagues about the efficacy of diet education on the performance of type 2 diabetic patients (27), Sharifirad and colleagues about the application of the health belief model on nutritional performance in diabetic patients (28), Gucciardi and colleagues on nutrition and blood sugar control in diabetic patients in Canada (29), and the study of group of researchers on 91 diabetic patients with mean age of 73 years in America. This group examined the role of educational interventions in diets and they stated that such interventions have been effective in improving food behaviors and blood sugar control of diabetic patients (30). Therefore, educating diabetic patients about the importance of proper nutrition during the courses and following it up after, can be effective in nutritional performance. So, according to the importance of having proper diet by type 2 diabetic patients, it is recommended to hold such educational courses in this field in health centers and other diabetic related organizations. It is crystal clear that holding such educational courses on a regular basis and by official organs of the country will have better results because of the availability of appropriate educational facilities and spaces as well as educated experts. Although as previously mentioned, individualized educational interventions, in order to increase awareness and to change the attitudes, would be inadequate, and supportive interventions to remove social, economic, environmental and cultural barriers along the educational interventions should be planned and applied (25-32). In this study, the mean number of fish intake per week in participants was not statistically significant before or after the educational intervention which shows that performed educational intervention has not been effective on the amount of fish intake by participants. It can be said that several factors are related to nutritional behavior, including income rate, occupation, level of education, economic and social factors, household, knowledge and attitude towards the importance of nutrition on health, personality characteristics, quality, taste, availability, easy cooking, nutritional value, price, smell, perceived barriers and perceived interests, the ability of food analysis and the skill of food choice (33-37). So, it is recommended to perform educational interventions including education on how to bake fish and how to omit the fishy smell, or to improve peoples' judgement when choosing high quality fish, etc. with the purpose of improving the amount of fish intake in order to have an impact on the above factors. The point to remember is that only increasing awareness about nutrition value and the benefits of fish intake on health is not enough. One of the most important factors influencing the amount of fish intake is monthly income (38-39). Considering the mean income of the participants in the present study (530 thousand Tomans per month), maybe participants can't afford to buy fish and also changing people's taste needs a longer time. According to the importance of fish intake by diabetics, it is recommended to health officials and policy makers to prepare facilities for diabetics to buy fish with economic prices. The mean consumption of vegetable oil increased after the educational intervention but it was not statistically significant. To justify this issue, it is clear that changing attitudes about the type of oil consumption would be difficult, and requires more than three months. Based on the findings of this study, the mean number of days per week with intense physical activity among participants before and after the educational intervention was not statistically significant but the mean number of days per week with moderate physical activity, after the educational intervention among participants was significantly increased. To justify this issue, since the mean age of the participants in this study was 56 years, age could be considered as the main reason for lack of increase in intense physical activity after the educational intervention, as well as other barriers like hypoglycemia, high weight, foot 
protection, etc. Whereas doing a moderate physical activity (like 10 minutes of fast walking, swimming, slow and recreational cycling), regarding age, diseases and physical conditions of patients would not be very difficult. In this study, fasting blood sugar of participants was significantly reduced after the educational intervention, so our intervention has been effective in reducing fasting blood sugar. Relatively comparable results were obtained from the study carried out by Kashfi and colleagues regarding the effect of educating about nutrition and jogging, on the blood sugar of type 2 diabetic patients of Nader Kazemi clinic in Shiraz (17). Many studies show the effectiveness of nutrition and physical activity interventions in reducing fasting blood sugar of diabetics which are similar to the results of our study (39-40). Three months after the educational intervention, the level of $\mathrm{HbA}_{1 \mathrm{c}} \mathrm{was}_{\mathrm{significantly}}$ reduced in participants, and shows the effectiveness of nutrition and physical activity interventions in proper control of blood sugar that prevents many dangerous complications of diabetes. It is estimated that every $1 \%$ reduction in $\mathrm{HbA}_{1 \mathrm{c}}$, reduces $37 \%$ of the micro vascular complications and $21 \%$ of macro vascular complications of diabetes (17). The study done in Yazd diabetes center by Baghyani Moghadam shows that the mean level of $\mathrm{HbA}_{1 \mathrm{c}}$ of 84.9 before the educational intervention, reached 7.28 after the educational intervention. This significant reduction in the level of $\mathrm{HbA}_{1 \mathrm{c}}$ has been due to the long duration of intervention (5 months) (41), so if our study took in a longer time (more than 3 months), we would be able to meet the same result. Other studies of educational interventions also represent the effectiveness of nutrition and physical activity intervention in reducing $\mathrm{Hb}_{1 \mathrm{c}}$ in diabetic patients which are similar with the results of our study (39-40). With regard to the importance of these two laboratory parameters (fasting blood sugar and $\mathrm{HbA}_{1 \mathrm{c}}$ ), reduction in these parameters indicates the effectiveness of the educational interventions in controlling diabetes, and it would be a motivation to design and implement next educational interventions. In this study, there was no significant difference in the mean weight, waist circumference and the body mass index of participants before and after the educational intervention. So, it appears from results that the reduction in weight, waist circumference and body mass index of participants by using nutrition and physical activity interventions requires more than three months. Changing behavior patterns requires a great transformation which means that along with changing values, attitudes, and behavior of individuals, the support of senior managers should be considered. Therefore, it is suggested to pay attention to the supportive role of senior managers in order to promote the culture of a diabetic's lifestyle and to establish the basic foundations of this culture in health organizations and the community.

\section{Study limitation}

The absence of a control group to compare the results of this study was one of our study limitations. Moreover, this study was not designed on the basis of existing models in health education. Therefore, the implementation of supportive-educational interventions based on the health education models, including the health belief model, the theory of planned behavior etc. along with a control group, in order to make better and more effective results in the field of improving nutrition and physical activity of diabetic patients is recommended. Diabetic patients need to receive educational-supportive interventions to successfully control their blood sugar levels and disease complications to improve their knowledge and nutritional performance and physical activity.

\section{Conclusions}

The study results are acceptable in reducing the level of fasting blood sugar and $\mathrm{HbA}_{1 \mathrm{c}}$ of participants after the educational intervention in comparison with the results before the educational intervention and it shows the impact of educational intervention on type 2 diabetic patients, so proper education in the field of diet and proper physical activity and an increase in the performance score of the individuals in mentioned fields can control the blood sugar in diabetic patients. In addition, control, monitoring and educational follow-up for such programs is recommended. The results of this research can be used as a basis for future researches like the design and evaluation of educationalsupportive interventions based on health education models including the health belief model, the theory of planned behavior, the social cognitive theory, the ecology, etc. along with the control group.

\section{Acknowledgments:}

The authors would like to express their gratitude to Niknejad health center staff. We would also like to thank all participants for participating in this study.

\section{Conflict of Interest:}

There is no conflict of interest to be declared.

\section{Authors' contributions:}

All authors contributed to this project and article equally. All authors read and approved the final manuscript. 


\section{References:}

1) Tol A, Alhani F, Shojaizadh D, Sharifirad G. Empowerment Approach to Promote Quality of Life and SelfManagement among Type 2 Diabetic Patients. J Health Syst Res. 2011; 7(2): 157-68.

2) Afshari M, Tol A, Taghdisi MH, Azam K. The effect of BASNEF-based blended educational program on on diabetes control among type 2 diabetic patients referred to diabetes clinic of Samirom city. Razi Journal of Medical Sciences. 2015; 22(132): 56-62.

3) Sorani M, Taghdisi MH, Shojaei Zadeh D, Novin L, Noroozi M, Fallahi S. Predictors of Self-Care Behaviors of Patients with Type 2 Diabetes. J Health Syst Res. 2012; 8(5): 814-23.

4) Wild S, Roglic G, Green A, Sicree R, King H. Global prevalence of diabetes. Diabetes care. 2004; 27(5): 1047-53. doi: 10.2337/diacare.27.5.1047.

5) Zimmet P. The burden of type 2 diabetes: are we doing enough? Diabetes \& metabolism. 2003; 29(4): 6S96S18. doi: 10.1016/S1262-3636(03)72783-9.

6) Heidari M, Alhani F, Kazemnejad A, Moezzi F. The effect of empowerment model on quality of life of Diabetic adolescents. Iranian Journal of Pediatrics. 2007; 17(Suppl 1): 87-94.

7) Larejani B, Zahedi F. Epidemiology of diabetes mellitus in Iran. Iranian Journal of Diabetes and Lipid Disorders. 2001; 1(1): 1-8.

8) Babaee QR, Soltanian AR, Khalkhaly HR, Rabieian M, Bahreini F, Afkhami Ardekani M. People Awareness on Diabetes Disease and Complications in Bushehr, Iran using Linears Models. Payavard Salamat. 2007; 1(1): 52-8.

9) Noroozi A, Tahmasebi R, Ghofranipour F, Hydarnia A. Effect of Health Promotion Model (HPM) Based Education on Physical Activity in Diabetic Women. Iran J Endocrinol Metab. 2011; 13(4): 361-7.

10) Vermeire E, Wens J, Van Royen $P$, Biot $Y$, Hearnshaw H, Lindenmeyer A. Interventions for improving adherence to treatment recommendations in people with type 2 diabetes mellitus. Cochrane Database Syst Rev. 2005; (2): CD003638. doi: 10.1002/14651858.CD003638.pub2. PMID: 15846672.

11) Vermeire E, Hearnshaw H, Van Royen P, Denekens J. Patient adherence to treatment: three decades of research. A comprehensive review. J Clin Pharm Ther. 2001; 26(5): 331-42. doi: 10.1046/j.13652710.2001.00363.x. PMID: 11679023.

12) King H, Aubert RE, Herman WH. Global burden of diabetes, 1995-2025: prevalence, numerical estimates, and projections. Diabetes care. 1998; 21(9): 1414-31. doi: 10.2337/diacare.21.9.1414. PMID: 9727886.

13) Morowatisharifabad MA, Rouhani Tonekaboni N. The Relationship between Perceived Benefits.Barriers of Self-care Behaviors and Self Management in Diabetic Patients. Hayat. 2007; 13(1): 17-27.

14) Rezagholizadeh A, Heshmat R, Larijani B. Iranian diabetes guidelines: methods and obejectives. Iranian Journal of Diabetes and Lipid Disorders. 2007; 7(1): 115-20.

15) Baghianimoghadam MH, Afkhami M, Ardakani SS, Mazloomi M, Saaidizadeh M. Quality of life in diabetic type II patients in Yazd. Journal of Shahid Sadoughi University of Medical sciences. 2006; 4(14): 49-54.

16) Hazavehei SM, Sabzmakanv L, HassanZadeh A, Rabiei K. The effect of Precede-Model-based educational program on depression level in patients with coronary artery bypass grafting. The Journal of Qazvin University of Medical Sciences \& Health Services. 2008; 2(12): 32-40.

17) Kashfi S, Khani JA, Bahadori KR, Hatami M. Evaluation of the Effects of Educating about Nutrition and Jogging on the Blood Sugar of Type II Diabetic Patients of a Clinic in Shiraz, Iran. Hakim Research Journal. 2009; 12(3): 54-60.

18) Nasehi MM, Moosazadeh M, Amiresmaeili M, parsaee M, Zakizadeh R, Mirzajani M. Prevalence of Five Main Risk Factors of Non-Communicable Diseases in Mazandaran Province: A Population Based Study. J Mazandaran Univ Med Sci. 2012; 21(86): 193-202.

19) Jayawardena R, Byrne NM, Soares MJ, Katulanda P, Hills AP. Food consumption of Sri Lankan adults: an appraisal of serving characteristics. Public health nutrition. 2013; 16(4): 653-8. doi: 10.1017/S1368980012003011. PMID: 22784794.

20) Farvid M, Rabiee S, Homayoni F, Rashidkhani B, Arian V. Determinants of fruit and vegetable consumption in type 2 diabetics in Tehran. Iranian Journal of Endocrinology and Metabolism. 2010; 12(2): 89-98.

21) Kasaeyan N, Forghani B, Faghih Imani B, Hoseinpour M, Amini M. The relationship between food habits and fasting blood sugar and glycosylated hemoglobin in (type 2) diabetics. Iranian Journal of Endocrinology and Metabolism. 2002; 4(1): 9-13. 
22) Delpisheh A, Azizi H, Dantalab Esmaeili E, Haghiri L, Karimi G, Abbasi F. The quality of care and blood sugar control in type II diabetic patients of rural areas under the care by family physicians. Iranian Journal of Diabetes and Metabolism. 2016; 14(3): 189-98.

23) Asif M. The prevention and control the type-2 diabetes by changing lifestyle and dietary pattern. J Educ Health Promot. 2014; 3(1): 1. doi: 10.4103/2277-9531.127541. PMID: 24741641, PMCID: PMC3977406.

24) Kobayashi Y, Hattori M, Wada S, Iwase H, Kadono M, Tatsumi H, et al. Assessment of daily food and nutrient intake in Japanese type 2 diabetes mellitus patients using Dietary Reference Intakes. Nutrients. 2013; 5(7): 2276-88. doi: 10.3390/nu5072276. PMID: 23803740 , PMCID: PMC3738973.

25) Yeh MC, Ickes SB, Lowenstein LM, Shuval K, Ammerman AS, Farris R, et al. Understanding barriers and facilitators of fruit and vegetable consumption among a diverse multi-ethnic population in the USA. Health Promot Int. 2008; 23(1): 42-51. doi: 10.1093/heapro/dam044. PMID: 18182418.

26) Dizaji MB, Taghdisi MH, Solhi M, Hoseini SM, Shafieyan Z, Qorbani M, et al. Effects of educational intervention based on PRECEDE model on self care behaviors and control in patients with type 2 diabetes in 2012. J Diabetes Metab Disord. 2014; 13(1): 72. doi: 10.1186/2251-6581-13-72. PMID: 25075380, PMCID: PMC4114427.

27) Heydari GH, Moslemi S, Montazeri Far F. Efficacy of education on knowledge, attitude \& practice of type II diabetic patients in relation to correct nutrition. Tabib-E-Shargh, Journal of Zahedan University of Medical Sciences and Health Services. 2003; 4: 207-13.

28) Sharifirad Gh, Entezari M, Kamran A, Azadbakht L. Efficacy of nutrition education to diabetic patient: Application of health belief model. Iranian Journal of Diabetes and Lipid Disorders. 2008; 7: 379-86.

29) Gucciardi E, Demelo M, Lee RN, Grace SL. Assessment of two culturally competent diabetes education methods: individual versus individual plus group education in Canadian Portuguese adults with type 2 diabetes. Ethn Health. 2007; 12(2): 163-87. doi: 10.1080/13557850601002148. PMID: 17364900.

30) Redmond EH, Burnett SM, Johnson MA, Park S, Fischer JG, Johnson T. Improvement in A1C levels and diabetes self-management activities following a nutrition and diabetes education program in older adults. $\mathrm{J}$ Nutr Elder. 2006; 26: 83-102. doi: 10.1300/J052v26n01-05. PMID: 17890205.

31) Vameghi R, Mohammad K, Karimloo M, Soleimani F, Sajedi F. The effects of health education through face to face teaching and educational movies, on suburban women in childbearing age. Iran J Public Health. 2010; 39(2): 77-88. PMID: 23113010, PMCID: PMC3481752.

32) Anderson AS, Campbell DM, Shepherd R. The influence of dietary advice on nutrient intake duringpregnancy. Br J Nutr. 1995; 73(2): 163-77. doi: 10.1079/BJN19950021. PMID: 7718538.

33) Verbeke W, Vackier I. Individual determinants of fish consumption: application of the theory of planned behaviour. Appetite. 2005; 44(1): 67-82. doi: 10.1016/j.appet.2004.08.006. PMID: 15604034.

34) Bruns K, Verbeke W, Olsen SO, Jeppesen LF. Motives, barriers and quality evaluation in fish consumption situations: Exploring and comparing heavy and light users in Spain and Belgium. British Food Journal. 2009; 111(7): 699-716. doi: 10.1108/00070700910972387.

35) Spinks A, Bose S. Factors affecting households' seafood purchasing decisions in Auckland, New Zealand: an empirical analysis. International Journal of Consumer Studies. 2002; 26(1): 62-70. doi: 10.1046/j.14706431.2002.00219.x.

36) Rortveit AW, Olsen SO. The role of consideration set size in explaining fish consumption. Appetite. 2007; 49(1): 214-22. doi: 10.1016/j.appet.2007.02.005. PMID: 17383770.

37) Petrenya N, Dobrodeeva L, Brustad M, Bichkaeva F, Menshikova E, Lutfalieva G, et al. Fish consumption and socio-economic factors among residents of Arkhangelsk city and the rural Nenets autonomous area. Int J Circumpolar Health. 2011; 70(1): 46-58. doi: 10.3402/ijch.v70i1.17798. PMID: 21329575.

38) Hupkens CL, Kinbbe RA, Drop MJ. Social class diferences in dietary habits described by food frequency questions- result from Denmark. Eur J Clin Nutr. 2003; 57(2): 1586-97. doi: 10.1038/sj.ejcn.1601728.

39) Shamsi M, Sharifirad GHR, Kachouei A, Hassanzadeh A. The effect of educational program walking based on health belief model on control sugar in woman by type 2 diabetics. Iranian Journal of Endocrinology and Metabolism. 2010; 11(5): 490-9.

40) Khani Jeihooni A, Kashfi M, Hazavehei MM. Effects of the BASNEF model-based educational programs on blood sugar control,(Type 2 Diabetes). Health Education \& Health Promotion. 2013; 1(1): 33 -49.

41) Baghyani-Moghadam M, Shafiei F, Haydarneia A, Afkhami M. Efficacy of BASNEF model in controlling of diabetic patients in the city of Yazd, Iran. Indian J Community Med. 2005; 30(4): 10-2. 